\title{
Aporte de la Ultrasonografía al Resultado de la Punción Vesical Suprapúbica en Lactantes y Recién Nacidos
}

\author{
Dr. José M. Ugarte S. 1; Dt. Carlos Hidalgo S. ${ }^{2}$; Dra. Mercedes Ruiz F. ${ }^{3}$ \\ Suprapubic Puncture Success Rates and Ultrasound Bladder \\ Anteroposterior Diameter
}

\begin{abstract}
A rematkable improvement in the efficacy of suprapubic puncture for urine sample collections was observed prospcctively by performing abdominal ultrasound measurements of the bladder's antero posterior diameter (UBAD) prior to the procedure: 63 suprapubic punctures were performed in 54 infants, one day to 24 months of age, all with clinically suspected urinary tract infections. Attempts to obtain urine samples in this way were always successful when the UBAD exceeded $3.5 \mathrm{~cm}$ and always failed when it was $2 \mathrm{~cm}$ or less. Intermediate success rates (36.4 to $88.8 \%$ ) were obtamed with UBAD 2.1 to $3.5 \mathrm{~cm}$. The main advantage of this method is that it potentially avoids unnecessarily unsucessful suprapubic punctures as when they are performed blindly.
\end{abstract}

(Key words: Suprapubic bladder puncture. Ultrasound. Bladder anteroposterior diameter).

Una manera frecuente de obtener orina en lactantes y recién nacidos para examen bacteriológico es la aspiración suprapúbica percutánea de contenido vesical ${ }^{1}{ }^{2}$ o punción vesical suprapúbica (P.V.S.). Esta técnica está indicada especialmente para distinguir bacteriuria verdadera de la contaminación uretral, con o sin cateterismo. ${ }^{1-6}$.

Sin embargo para obtener orina se requiere de una vejiga llena, lo que normalmente se evalúa indirectamente, a través de la falta de emisión por un tiempo determinado o por la palpación vesical $1,2,3,5,6$. Obtener esta condición en lactantes y recién nacidos es dificil pues no es posible solicitarles que retengan orina voluntariamente, to que significa una alta proporción de fracasos en el intento.

La ultrasonografía permite visualizar nítida $y$ directamente la orina en el lumen vesical, lo que nos indujo a utilizarla para intentar mejorar el rendimiento de esta técnica. Goldberg y Cols. en

1. Instructor Segundo. Depto. Pediattía y C. Infantil (C). División Ciencias Médicas Sur. Facultad de Medicina. Universidad de Chile. Hospital Paula Jaraquemada.

2. Profesor Auxiliar. Depto. Pediatría y C. Infantil (C). División Ciencias Médicas Sur. Facultad de Medicina, Universidad de Chile. Sub-Jefe Servicio de Pediatria. Hospital Paula Jaraquemada.

3. Profesor Asociado. Depto. Obstetricia y Ginecología. División Ciencias Médicas Sur. Facultad de Medicina, Universidad de Chile. Jefe Unidad de Ecografía. Hospital Paula Jaraquemada.
1972 realizaron una experiencia similar puncionando la vejiga de recién nacidos a través de un transductor para biopsia, de ecografía modo A (unidimensional) ${ }^{1}$.

Con el propósito de mejorar el rendimiento de la P.V.S. tratamos de identificar mediante ecogra. fía los rangos de diámetro vesical anteroposterior (A.P.) que suponen mayores probabilidades de obtener muestras de orina, estudiar el rendimiento de la P.V.S. realizada "a ciegas", verificar si existen algunos lactantes en que no es posible alcanzar un llene vesical mínimo compatible con el buen resultado de la P.V.S. y si la edad y el sexo tienen efecto sóbre su rendimiento.

\section{MATERIAL Y METODO}

En este estudio se emplearon tres ecúgrafos bidimensionales (Siemens 735 con transductor lineal de 3,5 MHz.; Philips Sonodiagnostic $\mathbf{R}$. con transductor lineal de $3,5 \mathrm{MHz}$. y Aloka 710 con transiductores sectoriales de 3 y $5 \mathrm{MHz}$.). Las punciones vesicales se realizaron con técnica aséptica mediante jeringas desechables de $10 \mathrm{ml}, y$ agujas hipodérmicas desechables de $0,8 \times$ $30 \mathrm{~mm}$.

Para el estudio se seleccionaron 54 niños ( 32 varones), cuyas edades estaban entre 1 día y 5 meses en 24 $(44,4 \%) ; 6$ a 11 meses en 16 (29.6\%); 12 a 17 meses en $9(16.7 \%)$ y 18 a 24 meses en 5 casos $(9.3 \%$. En todos ellos se habia obtenido previamente orina por micción, por sospechar infección del tracto urinario (I.T.U.), cuyos resultados se consideraton dudosos o insatisfactorios for contaminación con deposiciones, discordancia entre el sedimento y el resultado del cultivo o desarrollo de múltiples bacterias en este último. Sólo se excluyeron 
del protocolo los niños que, cumpliendo los requisitos descritos, no pudiesen ser trasladados a la unidad de cografía por su gravedad.

En todos los pacientes se instaló un recolector de orina para aprovechar la muestra cuando ésta era emitida espontaneamente durante el estudio $y$ para inhibir la micción (como se observa empíricamente en algunos casos). Inmediatamente después se dió agua en abundancia a beber o se aumentó el flujo de los líquidos parenterales según el caso. Treinta minutos más tarde, se realizaron ecografias para medir el diámetro anteroposterior de la vejiga, repitiéndolas cada 15 minutos liasta que éste fuese mayor de $1 \mathrm{~cm}$. Las ecografías y las punciones fueton siempre realizadas, cada procediniento, por una misma persona respectivamente. Las punciones se hicieron $2 \mathrm{~cm}$. por encima del pubis, en la línea modia y perpendicularmente con respecto a la picl, después de retirar la jalea de interfase ecográfica y limpiar la zona con atcohol yodado. Cuando la P.V.S. fracasó, se repitió el intento en los días siguicntes con diámetros vesicales iguales o mayores al del primer procedimiento. Por esta razón el numero de punciones $(\mathrm{N}=63)$ fue mayor que el de los pacientes $(n=54)$. En algunos niños no fue posible realjzar P.V.S. porque no alcanzaron los diámetros requeridos.

\section{RESULTADOS}

En 54 nifios se realizaron 126 ecografías $(\bar{X}=$ 2,3 por paciente) y 63 intentos de punción vesical, en 38 de los cuales se tuvo buen éxito. En la Tabla 1 es posible observar que de los 25 intentos fallidos, 13 ocurrieron en igual número de casos en que el diámetro vesical era menor que $2 \mathrm{~cm}$. y que prácticamente no hubo fracasos cuando el diámetro era mayor de $3 \mathrm{~cm}$. (sólo 1/8 en el rango de 3,1 a $3,5 \mathrm{~cm}$.).

En la Tabla 2 mostramos que el $55,7 \%$ de los nifrios estudiados tenian un diámetro vesical A.P. igual o menor que $2 \mathrm{~cm} .30$ minutos después de la instalación del recolector de orina y sólo $10 \%$ tenían diámetros superiores a $3,6 \mathrm{~cm}$. (100\% de buen éxito en el intento de P.V.S.), en otras palabras, la posibilidad de obtener una muestra de orina por punción suprapúbica sin ecografia habría sido de sólo $20 / 70$ intentos (Tabla 3), $28,6 \%$, atendiendo la distribución de los diáme. tros anteroposteriores encontrados y la frecuencia de fracasos o éxitos en cada grupo de incrementos de $0.5 \mathrm{~cm}$. del mismo.

En 16 pacientes $(30 \%)$ no logramos obtener muestra de orina con este método porque nunca alcanzaron el diámetro vesical mínimo requerido. En este grupo de niños que no se contienen, se podría intentar la punción vesical dirigida con un transductor para biopsia, procedimiento que ya

Tabla 1.

Eficacia de la P.V.S. según el Diámetro Antcroposterior encontrađo en la vejiga

\begin{tabular}{|c|c|c|c|c|c|c|c|c|}
\hline \multirow[b]{2}{*}{ P.Y.S. } & \multicolumn{7}{|c|}{ DLAMETRO VESICAL A.P. (en centímetros) } & \multirow[b]{2}{*}{ Total } \\
\hline & 1,1 a 115 & 1,6 a 2 & 2,1 a 2,5 & 2,6 a 3 & 3,1 a 3,5 & 3,6 a 4 & $4,10+$ & \\
\hline $\begin{array}{c}\text { :xitosa } \\
(+)\end{array}$ & 0 & 0 & 4 & 11 & 8 & 10 & 5 & 38 \\
\hline $\begin{array}{c}\text { Frustra } \\
\qquad(-)\end{array}$ & 5 & 8 & 7 & 4 & 1 & 0 & 0 & 25 \\
\hline Total & 5 & 8 & 11 & 15 & 9 & 11 & 5 & 63 \\
\hline $\begin{array}{l}\text { Wde éxito } \\
\text { (Etficacia) }\end{array}$ & 0 & 0 & 36,4 & 73,3 & 88,8 & 100 & 100 & \\
\hline
\end{tabular}

Tabla 2.

Dímetro Visical A.P. en Primera F.cografía. (t)

\begin{tabular}{|c|c|c|c|c|c|c|c|c|c|}
\hline \multicolumn{9}{|c|}{ DIAMFTRO VESICAL A.P. (en $\mathrm{cm}$.) } & \multirow[b]{2}{*}{ Total } \\
\hline $0-0.5$ & $0,6-1$ & $1-1,5$ & $1,6-2$ & $2,1-2,5$ & $2,6-3$ & $3,1-3,5$ & $3,6-4$ & $4,00+$ & \\
\hline 3 & 10 & 17 & 9 & 14 & 5 & 5 & 4 & 3 & 70 \\
\hline $4,2 \%$ & $14,3 \%$ & $24,3 \%$ & $12,9 \%$ & $20 \%$ & $7,1 \%$ & $7,1 \%$ & $5.7 \%$ & $4,3 \%$ & 10 \\
\hline
\end{tabular}


estamos realizando $y$ es motivo de un nuevo estudio.

El analisis de nuestros resultados no demostró diferencias significativas entre ambos sexos, como tampoco al estudiar la muestra dividida en rangos de edad, aunque es necesario hacer notar que el número de casos no permite sacar conclu. siones definitjyas el respecto. tho requiere más de treinta segundos. En ninguna de las muestras así obtenidas se encontró gérme. nes atribuibles a contaminación externa y por el contrario, la gran mayoría de los cultivos resultaron negativos.

Creemos por tanto que la ecografia es de gran utilidad para mejorar la técnica y el rendimiento de la P.V.S.

Tabla 3.

Probabilidades đe éxito de una P.V.S. a ciegas

\begin{tabular}{|c|c|c|c|c|}
\hline $\begin{array}{l}\text { Diámetro } \\
\text { Vesical AP }\end{array}$ & $\begin{array}{l}\text { (A) No de Casos } \\
\text { 1a. Eoograría }\end{array}$ & $\begin{array}{r}\% \text { Eficacia } \\
\text { (Cuadro 3) }\end{array}$ & $\begin{array}{l}\text { (B) Factor } \\
\text { Conversión* }\end{array}$ & $\begin{array}{l}(\mathrm{A}) \times(\mathrm{B}){ }^{* * *} \\
\text { No de casos con pro- } \\
\text { babilidades de éxito }\end{array}$ \\
\hline Menos de $2 \mathrm{~cm}$ & 39 & 0 & 0 & 0 \\
\hline 2,1 a $2,5 \mathrm{~cm}$. & 14 & 36,4 & 0,364 & 5 \\
\hline 2,6 a $3 \mathrm{~cm}$. & 5 & 73,3 & 0,733 & 4 \\
\hline 3,1 a $3,5 \mathrm{~cm}$. & 5 & 88,8 & 0,888 & 4 \\
\hline $3,6 \mathrm{~cm}$ o más & 7 & 100 & 1 & 7 \\
\hline Total & $70(100 \%)$ & & & $20(28,6 \%)$ \\
\hline
\end{tabular}

\section{DISCUSION}

Hay publicaciones que exhiben rendimientos de basta $90 \%$ para la P.V.S. ${ }^{2}$, pero las condiciores de preparación son tan estrictas que, finalmente, la mayoria de los niños en los cuales el procedimiento está indicado no pueden ser puncionados porque orinan antes de alcanzar una vejiga palpable, o 60 minutos con pañal o recolector seco ${ }^{1,2}$. Con la preparación de 30 minutos con recolector seco pudimos deducir en nuestro estudio que la probabilidad de éxito de la P.V.S. convencional (a ciegas) es de sólo $28,6 \%$. Al incorporar la ecografía previa a la P.V.S. evitamos un gran número de punciones destinadas al fracaso y podemos obtener un rendimiento de un $100 \%$ si esperamos que el diámetro vesical anteroposterior supere los $3,5 \mathrm{~cm}$.

No recomendamos proceder a la P.V.S. con diámetros vesicales inferiores a $2,1 \mathrm{~cm}$. puesto que en nuestra experiencia nunca logramos obtener orina.

E1 procedimiento no agregó ningún factor de riesgo al método convencional ya que no se consignó complicaciones atriburbles a él. Tampoco significó alargar demasiado dicho procedimiento ya que cada ecografía, para estos efectos,

\section{RESUMEN}

En un trabajo prospectivo, los investigadores demuestran como la técnica de la punción suprapuibica obtiene notable mejoría en su rendimiento al incorporar la ultrasonografía previal al procedimiento.

Para ello efectúan 63 punciones vesicales a 54 pacientes con diagnóstico presuntivo de infección del tracto urinario.

Obtuvieron rendimiento de un $100 \%$ cuando al medir el diámetro anteroposterior de la vejiga ecogŕaficamente, éste superaba los $3,5 \mathrm{~cm}$.

La principal ventaja del método consiste en evitar un gran número de punciones vesicales destinadas al fracaso al efectuar el procedimiento a ciegas.

\section{REFERENCLAS}

1. Gollberg, B.B, and Meyer, H.; Ulitasonically guided suprapubic urmary bladder aspiration. Pediatrics 51 : $70,1973$.

2. Nelson, J.D. and Peters, P.C.: Suprapubic aspitation of urine in premature and term infant. Pediatrics 36 : $132,1965$.

3. Pryles, C.U., Atkin, M.D., Morse, T.S., and Welch, 
K.J.: Comparative bacteriologic study of urine obtained from children by percutaneous suprapubic aspiration of the bladder and by catheter. Pediatrics 24: $983,1959$.

4. Pryles, C.l., Luders, D., and Alkan. M.K.: A comparative study of bacteria? cultures and colony counts in paired specimens of urine obtained by catheter vs. voiding from normal infants and infants witl urinary tract infection. Pedjatrics 27: 17, 1961.

5. Saccharow, L., and Pryles, C.U.: Further experience with the urmary bladder: Bacteriologic studies in 654 infants and children. Pediatrics 43; 1018, 1969.

6. Shannon, F.T., Sepp. F., and Rose, G.R.: Diagnosis of bacteriuria by bladder punture in infancy and childhood. Aust. Pediat. J., 5: 97, 1969. 